\title{
Hypericum perforatum versus fluoxetine in the treatment of mild to moderate depression: a randomized double-blind trial in a Brazilian sample Hypericum perforatum versus fluoxetina no tratamento da depressão leve a moderada: estudo duplo-cego randomizado em uma amostra brasileira
}

\author{
Ricardo Alberto Moreno, ${ }^{1}$ Chei Tung Teng, ${ }^{1}$ Karla Mathias de Almeida, ${ }^{1}$
} Hildeberto Tavares Junior ${ }^{2}$

\begin{abstract}
Objective: Hypericum perforatum has demonstrated antidepressant efficacy when compared to placebo, but comparisons with other antidepressants remain controversial. We assessed the efficacy and safety of Hypericum perforatum in comparison with fluoxetine, in a 8-week double-blind trial in patients with mild to moderate depression. Method: Seventy-two outpatients were randomly assigned to receive Hypericum perforatum $900 \mathrm{mg} /$ day, fluoxetine $20 \mathrm{mg} /$ day or placebo. Efficacy measures included the HAM-D scale, the Montgomery-Assberg Rating Scale, and the Clinical Global Impression. Safety was assessed with the UKU Side Effect Rating Scale. Results: Intention-to-treat analysis showed no differences between the mean scores of the three groups. In the analyses of observed cases, patients receiving Hypericum perforatum had the lowest remission rates (12\%, $p=0.016)$ compared to fluoxetine (34.6\%) and placebo (45\%). Conclusions: Hypericum perforatum was less efficacious than both fluoxetine and placebo. Both drugs were safe and well-tolerated. Larger trials are needed for definite conclusions.
\end{abstract}

Keywords: Hypericum perforatum; Fluoxetine; Depression; Antidepressive agents; Efficacy

Resumo

Objetivo: Hypericum perforatum demonstrou eficácia antidepressiva em comparação ao placebo, mas comparações com outros antidepressivos permanecem controversas. Avaliamos a eficácia e a tolerabilidade do Hypericum perforatum em comparação com fluoxetina e placebo, em um estudo duplo-cego de oito semanas em pacientes com depressão leve a moderada. Método: Setenta e dois pacientes ambulatoriais receberam aleatoriamente doses fixas de Hypericum perforatum $900 \mathrm{mg} /$ dia, fluoxetina $20 \mathrm{mg} /$ dia ou placebo. Medidas de eficácia incluíram a HAM-D ${ }_{21}$, Escala de Montgomery-Asberg e Impressão Clínica Global. A segurança foi avaliada por meio da Escala UKU de Efeitos Colaterais. Resultados: A análise por intenção de tratar não demonstrou diferenças entre os três grupos. Na análise por casos observados, os pacientes que receberam Hypericum perforatum tiveram as menores taxas de remissão (12\%, p =0,016), em comparação à fluoxetina (34,6\%) e ao placebo (45\%). Conclusões: Hypericum perforatum foi menos eficaz que fluoxetina e placebo. Ambas as drogas foram seguras e bem toleradas. Estudos conclusivos com uma maior amostra são necessários.

Descritores: Hypericum perforatum; Fluoxetina; Depressão; Antidepressivos; Eficácia

1 Affective Disorders Study Group, Institute of Psychiatry, Clinical Hospital, Medical School, Universidade de São Paulo (USP), São Paulo (SP), Brazil

2 Institute of Psychiatry, Clinical Hospital, Medical School, Universidade de São Paulo (USP), São Paulo (SP), Brazil

Financing: Supported, in part, by grants and drug supply

(Hypericum perforatum) from Marjan Ltd. Fluoxetine kindly donated by Eli Lilly Brazil.

Conflict of interests: Dr. Moreno reported having received lecture fees from Eli Lilly, Wyeth, Roche, Aché, Abbott, AstraZeneca (Pharmacia Upjohn), Marjan Farma and Eurofarma, and consulting fees from AstraZeneca (Pharmacia Upjohn), Wyeth, Roche, Eli Lilly, Organon, Bristol, Merck and Servier.

Submitted: 15 March 2005

Accepted: 13 June 2005

\section{Correspondence}

Ricardo Alberto Moreno

Rua Capote Valente, 423 - Conj 35

05409-001 São Paulo, SP, Brazil

Phone: (55 11) 3068-0150 Fax: (55 11) 3063-3417

E-mail: rmoreno@sti.com.br 


\section{Introduction}

Extracts of Hypericum perforatum (St. John's wort) have been widely used for the treatment of depression. Although its superiority over placebo has previously been demonstrated, ${ }^{1-3}$ results comparing Hypericum with other antidepressants remain controversial. Wheatley et al. compared Hypericum with amytriptiline and found no statistical significant difference in the first 6 weeks of treatment. ${ }^{4}$ After this period, amytriptiline showed a better response, where this delay could possibly be related to the $75 \mathrm{mg}$ daily used in the study, which could be considered low. Harrer et al. compared Hypericum perforatum with maprotiline in 102 patients during 4 weeks and found no difference between the treatments. ${ }^{5}$ Again, the dosage used in the study could be considered low (75 mg daily of maprotiline). Another study ${ }^{6}$ failed to demonstrate difference between amytriptiline $75 \mathrm{mg}$ and Hypericum perforatum.

Hypericum perforatum 900-1800 mg/day was compared with sertraline 50-100 mg/day in a double-blind multicenter trial which included 340 patients. ${ }^{7}$ Although no differences were found, this study has been criticized due to its possible bias caused by selection of treatment-resistant patients. ${ }^{8} \mathrm{~A}$ doubleblind randomized trial comparing Hypericum versus fluoxetine in patients with mild to moderate depression demonstrated that both drugs have the same efficacy but Hypericum perforatum has a significant better safety profile. ${ }^{9}$

Volz and Laux published a review of studies comparing the efficacy of Hypericum perforatum and fluoxetine and no significant differences were found. ${ }^{10}$ However, the studies included in this review had differences regarding the methodology and source of Hypericum (different St John's wort extracts). Another review ${ }^{11}$ concluded that doses of approximately 5001000 mg daily have a comparable efficacy to synthetic antidepressants in their normally prescribed dosages. Finally, a recent randomized placebo-controlled trial comparing Hypericum perforatum versus fluoxetine found that either fluoxetine or Hypericum were not more effective than placebo in short-term treatment of mild to moderate depression. ${ }^{12}$ In spite of controversial results from these recent trials, Hypericum perforatum has been prescribed for the treatment of depression mainly due to its favorable tolerability profile.

This study aimed to investigate the efficacy and safety of Hypericum perforatum (Iperisan ${ }^{\circledR}$, Marjan) in comparison with fluoxetine (Prozac ${ }^{\circledR}$, Eli Lilly) and placebo, in a randomized double-blind trial, during 8 weeks.

\section{Method}

\section{Subjects}

The study was approved by Institutional Ethic Committee at the Clinical Hospital, Medical School, Universidade de São Paulo. Patients were recruited through the Affective Disorders Study Group Unit at the Institute of Psychiatry and after an explanation of the study, written informed consent was obtained.

Outpatients aged 18 to 75 years, who were residing in the city of São Paulo and having mild to moderate, non-psychotic major depressive disorder according to the criteria of the Diagnostic and Statistical Manual of Mental Disorders, fourth edition (DSM-IV) ${ }^{13}$ were recruited.

The screening visit included a complete psychiatric and physical examination, the Hamilton Depression Rating Scale, ${ }^{14}$ 21 -item version $\left(H A M-D_{21}\right)$, vital signs, laboratorial tests and electrocardiogram. Patients were diagnosed according to the DSM-IV criteria based on interviews using the Structured Clinical Interview for DSM-IV - SCID. ${ }^{11}$
The eligibility criteria included a baseline score of at least 10 points in the Hamilton Depression Rating Scale, ${ }^{15} 21$-item version $\left(\mathrm{HAM}-\mathrm{D}_{21}\right.$ ) and a maximum baseline score of 24 points. Patients with other types of depression, psychosis, personality disorders such as borderline or depressive, bipolar disorders, suicidal ideation, uncontrolled organic disease, history of alcohol or drug abuse 1 year prior to the screening, who had abnormal laboratorial tests or a history of seizures and who had been treated with electroconvulsotherapy or had taken any investigational drug up to 30 days before screening were excluded. Patients who used MAO-inhibitors 2 weeks prior to the screening, other antidepressants or any other drug, except benzodiazepines in doses equivalent to diazepam $10 \mathrm{mg} /$ day p.o 1 week prior to the screening, and those who had already been treated with fluoxetine were also excluded.

\section{Study design}

This study was randomized, double-blind, with three parallel treatment arms.

Patients who met eligibility criteria had a 1-week washout with placebo before enrollment. Only patients who did not have a reduction in $H A M-D_{21}$ scores $\geqslant 20 \%$ at baseline visit were randomized After the washout period, patients were assigned to receive Hypericum perforatum 900 mg daily (300 mg t.i.d.), fluoxetine $20 \mathrm{mg} /$ day (20 mg in the morning and placebo capsules at lunchtime and at night), or placebo t.i.d, for 8 weeks. No other drug, except benzodiazepines in doses equivalent to diazepam $10 \mathrm{mg} /$ day p.o, was allowed during the study.

The primary efficacy measure was remission and response rates according to the HAM-D ${ }_{21}$ scale. Secondary outcomes included mean changes in HAM-D ${ }_{21}$ scores the MontgomeryÅsberg Depression Rating Scale ${ }^{16}$ (MADRS) and Clinical Global Impression (CGI) ${ }^{17}$ assessments. Efficacy was assessed in the baseline and weekly. Tolerability and safety were assessed in the baseline and weekly with the UKU Side Effect Rating Scale $^{18}$ and vital signs. Physical examination and laboratorial tests were performed at baseline and at the endpoint.

Raters were trained in the use of the assessment tools before the beginning of the study.

The study was conducted in compliance with the Declaration of Helsinki and its amendments and was approved by the institutional ethics committee. All subjects signed a written informed consent before recruitment.

\section{Statistical analysis}

Descriptive analysis was used for demographic data, whereas efficacy was assessed through the mean total scores of the HAM- $D_{21}$ and MADRS. Clinical response was defined as $50 \%$ decrease in $H A M-D_{21}$ or MADRS total scores, compared with baseline, and CGI assessments rated as 'better' or 'much better'. Remission was defined as total $H A M-D_{17}$ score $\leqslant 7$. The Chisquare and the Fisher's exact tests were used to evaluate the extent of the group's homogeneity.

Repeated measures analysis of variance (ANOVA) was used to compare continuous variables. For all tests, a significant level of 0.05 was established. Remission and response rates for each assessment, as well as comparisons between dropouts' rates, were analyzed with chi-square test.

\section{Results}

Eighty patients met eligibility criteria. Eight were excluded after the 1-week washout period. Seventy-two patients were randomized and 53 completed the 8 week-trial: 19 from 
placebo, 18 from Hypericum and 16 of the fluoxetine group. Dropouts did not differ between groups $(p=0.775)$. Six patients abandoned treatment and were lost to follow-up after enrollment, and therefore 66 patients were included in our ITT analyses.

The majority of the 53 patients who completed the study were female: 44 (83\%); there was no difference between groups regarding ratios of males and females. Age ranged from 19 to 64 years $(40.5$ years \pm 10.7$)$ and patients from the placebo group had a significantly higher mean age (45.9 years \pm 10.8 , $p=0.0301)$. Mean age in the fluoxetine group was 37.7 years \pm 9.9 and 37.2 years \pm 11.65 in the Hypericum group. The placebo group also had a higher percentage of moderate depression $(44.4 \%, p=0.018)$ than either the fluoxetine group (10.5\%) or the Hypericum group $(6.7 \%)$.

The intention-to-treat (ITT) analyses $(n=66)$, using the LOCF (last observation carried forward), did not demonstrate differences between the groups regarding total mean HAM-D ${ }_{21}$ scores $(p=0.2678)$ and mean HAM-D $D_{21}$ changes $(p=0.2130)$ (the initial HAM-D $D_{21}$ scores were subtracted from the final scores, then divided by the initial scores and the final value multiplied by 100 in order to obtain the percentage). All the three groups tended to achieve maximum improvement in the HAM-D scores at the $4^{\text {th }}$ week (Figure 1 ).

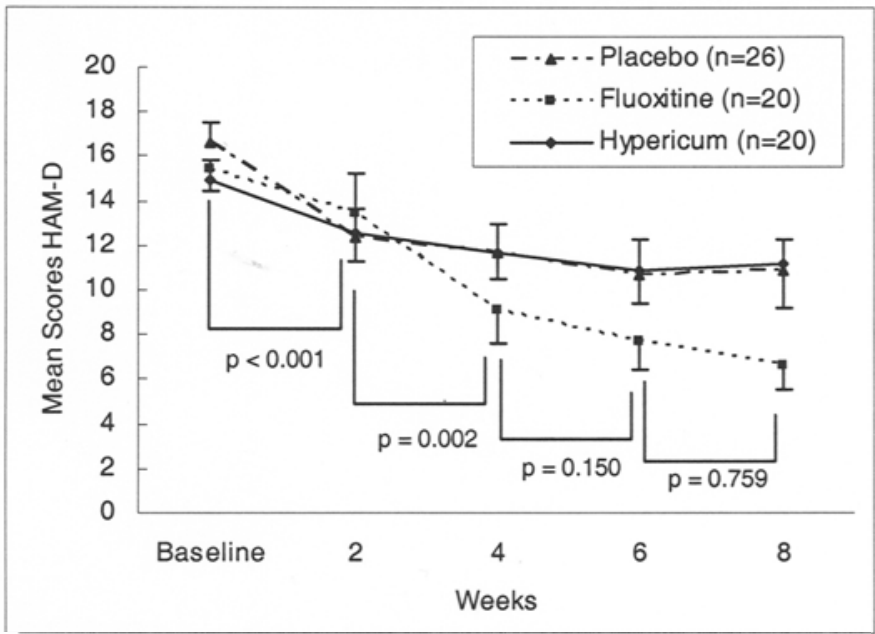

Figure 1 - Mean HAM- $D_{21}$ scores at each specified time in the intention to treat analysis.

The analyses of HAM-D $D_{21}$ total scores of all patients who completed 8 weeks of treatment $(n=53)$ (observed case [OC] analysis) showed no differences in the evolution throughout the study between the three groups ( $p=0.2203$ ) as well as no difference in the mean scores of the groups ( $p=0.3279$ ). Comparison between fluoxetine and Hypericum groups in the $8^{\text {th }}$ week, using ANOVA demonstrated a significant difference in HAM- $D_{21}$ score decrease, favoring fluoxetine $(p<0.05)$.

There were no differences between the three groups regarding MADRS ratings, in either the ITT or OC analyses.

There were no differences between the three groups regarding mean $\mathrm{CGl}$-severity scores in $\mathrm{OC}$ analyses. However, OC analysis showed that CGI-Improvement score was significantly lower in the fluoxetine group, indicating the best response, when compared with both placebo $(p=0.0288)$ and Hypericum ( $p=0.0039$ ) groups. CGI-Improvement scores in the Hypericum group were not significantly different from the scores in the placebo group ( $p=0.8826$ ).

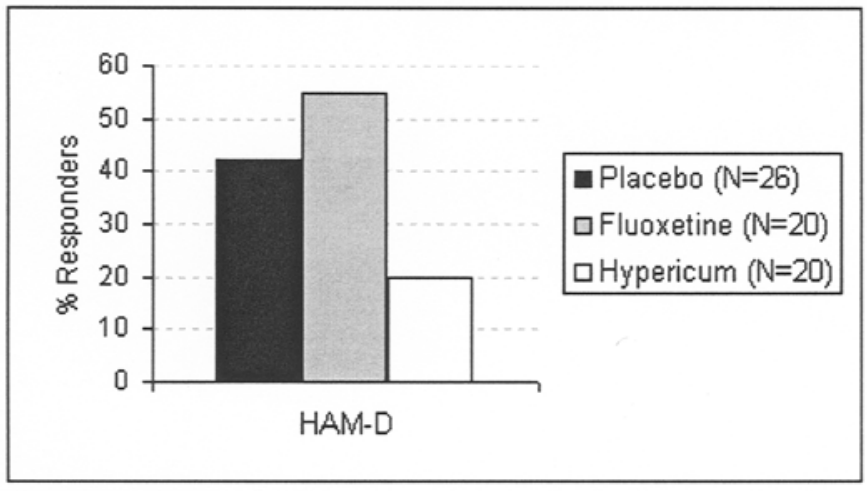

Figure 2 - Response rate (\%) in the intention to treat population, According to HAM-D scores. ${ }^{*} p \leq 0.05$; $n s=$ non significant

The ITT analysis of response rate demonstrated the lowest response to treatment in the Hypericum group, according to HAM-D 21 scores, when compared with both placebo and fluoxetine groups ( $p=0.021)$. Interestingly, fluoxetine and placebo demonstrated no significant difference in response rate in the same population and analysis ( $p=0.3794)$ - Figure 2 . The ITT analysis also showed the lowest remission rate in the Hypericum group ( $12 \%$; $p=0.0167$ ) when compared with either fluoxetine or placebo groups, whilst there were no differences between fluoxetine or placebo groups (34.6\% and $45 \%$, respectively; $p=0.44$ ) - Figure 3 .

There were no differences in the response rate between groups as measured by the MADRS.

Additionally, there were no differences between the three groups regarding safety measures, including vital signs. Tension, nausea, postural dizziness, menorrhagia and diminished sexual desire were more frequent in the fluoxetine group at week 4 . Those side effects tended to diminish with time and only menorrhagia persisted in a higher frequency in the fluoxetine group up the $8^{\text {th }}$ week. At the $8^{\text {th }}$ week, there was a higher incidence of insomnia, headache and diarrhea in the fluoxetine group.

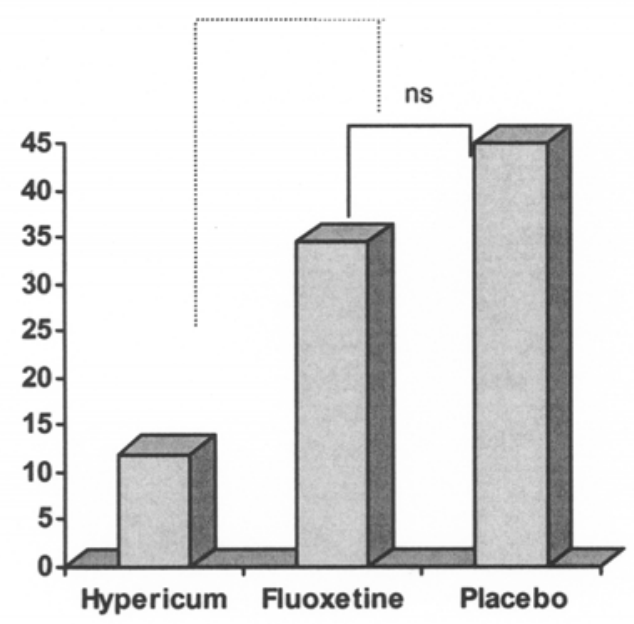

ns $=$ non-significant

${ }^{\star} p \quad 0.05$

Figure 3 - Remission rate (\%) in the intention-to-treat population, according to HAM-D scores. 


\section{Discussion}

The results of this trial failed to demonstrate significant benefits of Hypericum over either placebo or fluoxetine. The only significant results found in terms of efficacy were a significant decrease in HAM-D ${ }_{21}$ scores and a significant improvement at CGI-Improvement score in the fluoxetine group at the $8^{\text {th }}$ week of the trial on OC analysis. In addition, Hypericum had the lowest remission and response rates, when compared to both fluoxetine and placebo. Interestingly, remission and response rates of fluoxetine did not differ from response rates to placebo.

Although Hypericum has already demonstrated its superiority over placebo in several trials, ${ }^{1-3}$ and efficacy similar to fluoxetine in mild to moderate depression, ${ }^{14}$ our trial did not corroborate those results. However, we are unable to draw any marked conclusion due to the lack of previous analyses regarding the statistical power of the sample size. Patients included in this trial were classified as having mild or moderate depression according to HAM-D $D_{21}$ scores, but this does not rule out the inclusion of chronic refractory patients, which would decrease the effect size of the sample. On the other hand, the high rates of improvement obtained with placebo lead us to think that the inclusion of chronic treatment-resistant patients did not take place to any great extent, while the dosage of fluoxetine used in this study was possibly low for a number of patients. Hypericum perforatum was better tolerated than fluoxetine. However, the decrease in HAM-D $D_{21}$ scores in the fluoxetine group, which tended to stabilize after the $4^{\text {th }}$ week, was translated into more subjective improvements, as shown by CGI-I assessments.

\section{Conclusions}

In this small double-blind randomized placebo controlled trial, Hypericum perforatum 900 mg daily was less efficacious than placebo and fluoxetine in the treatment of outpatients with mild to moderate depression. Fluoxetine $20 \mathrm{mg}$ daily had the highest decrease in $H A M-D_{21}$ scores, but failed to demonstrate superiority over placebo in terms of response and remission rates in this population. Hypericum perforatum and fluoxetine were safe and well tolerated. Further trials with a larger sample are required in order to confirm those results.

\section{Acknowledgements}

The authors are grateful to Marjan, for the financial support and donation of Hypericum perforatum, and to Eli Lilly Brazil, for the donation of fluoxetine.

\section{References}

1. Hansgen KD, Vesper J, Ploch M. Multicenter double-blind study examining the antidepressant effectiveness of the Hypericum extract LI 160. J Geriatr Psychiatry Neurol. 1994;7(Suppl1):S15-8.

2. Linde K, Ramirez G, Mulrow CD, Pauls A, Weidenhammer W, Melchart D. St John's wort for depression - an overview and metaanalysis of randomized clinical trials. BMJ. 1996;313(7052):253-8.

3. Sommer H, Harrer G. Treatment of mild to moderate depression. Phytomedicine. 1994;1:3-8.

4. Wheatley D. LI 160, an extract of St. John's wort, versus amitriptyline in mildly to moderately depressed outpatients - a controlled 6-week clinical trial. Pharmacopsychiatr. 1997;30(Suppl 2):77-80.

5. Harrer G, Hübner W, Podzuweit $\mathrm{H}$. Effectiveness and tolerance of the Hupericum extract LI 160 compared to maprotiline: a multicenter double-blind study. J Geriatr Psychiatry Neurol. 1994;7(Suppl1):S24-8.
6. Vorbach EU, Arnoldt KH, Hubner WD. Efficacy and tolerability of St. John's wort extract LI 160 versus imipramine in patients with severe depressive episodes according to ICD-10. Pharmacopsychyatry. 1997;30(Suppl 2):81-5.

7. Hypericum Depression Trial Study Group. Effect of Hypericum perforatum (St John's wort) in major depressive disorder: a randomized controlled trial. JAMA. 2002;287(14):1807-14.

8. Wheatley D. St John's wort and depression. JAMA. 2002;288(4):446; author reply 448-9.

9. Schrader E. Equivalence of St John's wort extract (Ze 117) and fluoxetine: a randomized, controlled study in mild-moderate depression. Int Clin Psychopharmacol. 2000;15(2):61-8.

10. Volz HP, Laux P. Potential treatment for subthreshold and mild depression: a comparison of St. John's wort extracts and fluoxetine. Compr Psychiatry. 2000;41(2 Suppl 1):133-7.

11. Schulz V. Clinical trials with Hypericum extracts in patients with depression - results, comparisons, conclusions for therapy with antidepressant drugs. Phytomedicine. 2002;9(5):468-74.

12. Bjerkenstedt L, Edman GV, Alken RG, Mannel M. Hypericum extract LI 160 and fluoxetine in mild to moderate depression. A randomized, placebo-controlled multicenter study in outpatients. Eur Arch Psychiatry Clin Neurosci. 2005;255(1):40-7.

13. American Psychiatric Association. Diagnostic and statistical manual of mental disorders. 4th edition. Washington, DC: American Psychiatric Press; 1994.

14. Hamilton M. A rating scale for depression. J Neurol Neurosurg Psychiatry. 1960;23:56-62.

15. Spitzer RL, Williams JB, Gibbon M, First MB. The Structured Clinical Interview for DSM-III-R (SCID). I: History, rationale, and description. Arch Gen Psychiatry. 1992;49(8):624-9.

16. Montgomery SA, Asberg M. A new depression scale designed to be sensitive to change. Br J Psychiatry. 1979;134:382-9.

17. Guy W. Clinical Global Impressions. ECDEU assessment manual for psychopharmacology, rev. ed. National Institute of Mental Health 1976; US Dept. of Health, Education and Welfare Publication (ADM) 91-338, Rockville, MD.

18. Lingjaerde O, Ahlfors UG, Bech P, Dencker SJ, Elgen K. The UKU side effect rating scale. A new comprehensive rating scale for psychotropic drugs and a cross-sectional study of side effects in neuroleptic-treated patients. Acta Psychiatr Scand Suppl. 1987;334:1-100. 